\title{
ACUTE ORAL HYDRATION IN MANAGEMENT OF OLIGOHYDRAMNIOS AND DOPPLER CHANGES
}

By

\section{Mohamed Alaa Farghal, Abd El-Moneam Mohamed Zakaria and Abd El-Mosef Abd El-Hamed Sedek}

Department of Obstetrics \& Gynecology, Faculty of Medicine, Al-Azhar University

Corresponding author: Mohamed Alaa Farghal,

Mobile: (+20)1000849174, E-mail: m_farghal@ gmail.com

\begin{abstract}
Background: For many women, oligohydramnios is a time of reappraisal of behavior, nutrition, and lifestyle to ensure that their fetus has the best and healthiest start in life. Most pregnant women are likely to pay more attention to living healthily and eating a healthy diet than they did before pregnancy. Acute oral hydration is an effective way of increasing AFI. It is a noninvasive, easily accessible and cheap intervention, which should be encouraged.
\end{abstract}

Objective: To assess the effect of acute oral hydration on amniotic fluid index (AFI) and associated Doppler changes.

Patients and methods: This study was conducted at El-Mahalla General Hospital aiming to evaluate the role of maternal hydration on oligohydramnios and Doppler changes. A total of 40 pregnant ladies with oligohydramnios were included and they were divided into two equal groups; group A received oral hydration therapy, and group B received the normal amount of fluid intake.

Results: The mean AFI in group A before treatment was $3.6 \pm 1.3$ and in group B was $3.4 \pm 1.5$ with no significant difference between the two groups $(\mathrm{p}=0.367)$. The mean AFI in group A after treatment was $8.6 \pm$ 1.3 and in group B it was $5.8 \pm 1.2$ with statistically significant difference between the two groups $(\mathrm{p}=0.005)$. There was a statistically significant difference between the values of AFI before and after treatment in group A ( $\mathrm{p}<0.001)$, but not in group B (0.052).

Conclusion: Oral hydration therapy was effective in improving oligohydramnios status in pregnant women. Moreover, renal and uterine arteries pulsatility indices also improved via such method of management. Nevertheless, umbilical artery pulsatility and resistance indices showed non-significant improvement.

Keywords: Oligohydramnios, Amniotic fluid index, Umbilical artery Doppler, Uterine artery Doppler.

\section{INTRODUCTION}

Amniotic fluid serves to cushion the fetus allowing musculoskeletal development and protecting it from trauma. It also maintains temperature and has a minimal nutritive function. Amniotic fluid may promote growth and differentiation of tissues of the lung and gastrointestinal tract through inhalation and ingestion of the amniotic fluid respectively (Rabie et al., 2017).

Oligohydramnios is one of the prevalent threatening conditions to fetal health, with an incidence of $2.3 \%$. Intrauterine growth restriction, respiratory distress syndrome, post-maturity syndrome and chronic fetal hypoxia are associated with oligohydramnios. This 
condition may be responsible for fetal malpresentation, umbilical cord compression, meconium staining, increased prenatal mortality and morbidity and increased operative delivery (Rabinovich et al., 2019).

Different types of treatment are available or are under evaluation for oligohydramnios including oral hydration, 1-deamino [8-D-arginine] ,vasopressin administration and amnion infusion during labour, which, although effective is an invasive method and can only be performed during labour when the membranes have ruptured and must be kept under intensive observation for a long period (Hesson and Langen, 2017).

Because maternal dehydration increases the chance of oligohydramnios, hydration can be considered an effective way of decreasing the chance of the condition. Therefore, both serum and oral hydration therapies are hypothesized to be effective treatments for oligohydramnios. Previous studies have supported this hypothesis. Oral hydration efficacy has been evaluated and acute and chronic efficacies of this method have been assessed (Gizzo et al., 2015).

All women should be made aware of the importance of adequate fluid intake during pregnancy. However, it would be of even more importance for women with pregnancies at risk of uteroplacental insufficiencies, because inadequate fluid intake may cause further fetal compromise. Studies also point to the importance of maintaining adequate hydration during exercise, thermal exposure or gastrointestinal losses in pregnancy (Ali and Ahmed, 2018).
In addition to adequate fluid intake, patients with oligohydramnios and intrauterinefetal growth retardation should be encouraged to rest as much as possible in the lateral recumbent position, because this should optimize uteroplacental perfusion, which also may help to increase AFV as well as optimize fetal growth (Rawat, 2015).

An alternative route of maternal hydration is intravenous (iv) fluid loading, which was attempted as a method of volume expansion in women who were dehydrated or hypovolemic, and this corrected oligohydramnios as well as maternal plasma volume. Importantly, amniotic fluid volume has been reported to correlate with maternal plasma volume (Friedman and Ogunyemi, 2018).

The evaluation of amniotic fluid volume (AFV) is an established part of the antenatal surveillance of pregnancies at risk for an adverse pregnancy outcome. The two most commonly used ultrasound techniques to estimate AFV are the amniotic fluid index (AFI) and the single deepest pocket (SDP). Four studies have defined normal AFVs, and although their normal volumes have similarities, there are also differences primarily due to the statistical methodology used in each study (Uche et al., 2018).

Dye determined AFV correlates with ultrasound estimates for normal fluid volumes but correlates poorly for oligohydramnios and polyhydramnios. The addition of color Doppler in estimating AFV leads to the over diagnosis of oligohydramnios. Neither the AFI nor the SDP is superior in identifying oligohydramnios, but the SDP is a better measurement choice as the use of AFI 
increases the diagnosis rate of oligohydramnios and labor inductions without an improvement in pregnancy outcomes (Hughes and Magann, 2017).

The present work aimed to assess the effect of acute oral hydration on amniotic fluid index (AFI) and associated doppler changes.

\section{PATIENTS AND METHODS}

This study included 40 pregnant women who were already diagnosed to have oligohydramnios by ultrasound and attend the outpatient clinic ANC at ElMahalla general hospital and El Azhar University Hospitals during the period from October 2018 to February 2020.

Inclusion criteria $2.1<$ AFI $<6 \mathrm{~cm}$, no indication for emergency delivery, nonruptured membrane (diagnosed by fern $\&$ nitrate test) and gestational age more than 34 week.

Exclusion criteria: Patients with ruptured amniotic membranes, multiple pregnancies, post term pregnancy, heart disease, renal disease, moderate or severe preeclampsia and gestational age less than 34 week.

Written consents: were obtained from the pregnant women on whom the study was performed and they were informed about the objectives and hazards of the study.

\section{All patients were subjected to:}

\section{Personal history.}

\section{Family history.}

3. Menstrual history: Gestational age of present pregnancy determination according to last menstrual period and confirmation by ultrasound assessment.
4. Present history: Presence of uterine contraction. Associated symptoms: (bleeding, abdominal pain) and routine treatment first trimester like folic acid supplement.

\section{Obstetric history.}

6. Surgical history: (i) Any cervical surgeries. (ii) Previous cesarean section. (iii) Routine investigation in first trimester. Specific investigations of serum analysis were carried out for $\mathrm{LH}$, thyroid function test, free testosterone level, and oral glucose tolerance test.

7. General Examination: Vital signs. Chest \& heart examination and limbs examinations.

8. Abdominal examination: Inspection. Superficial palpation and for liver, spleen \& loin

9. Obstetric examination: Fundal level $\&$ fundal grip.

10. Per vaginal examination: For intact membranes and presentation.

11. Ultrasound examination: The ultrasound machine used was mindray DC7 device, with a curvilinear abdominal probe, 3.5 Hertz device at radiology department at El-Mahalla general hospital for:

- Evaluation of gestational age.

- Diagnosis of oligohydramnios (amniotic fluid index $<5 \mathrm{~cm}$ ).

- Detection of fetal viability.

- Fetal size and weight.

- Exclusion of multiple pregnancies.

- Fetal presentation and position.

- Evaluation of fetal malformations. 
- Placental location.

- Doppler of umbilical artery and uterine artery.

Amniotic fluid index was first measured for all participants \& then the participants divided into two groups, the first one was asked to drink $2 \mathrm{~L}$ of water within $2 \mathrm{~h}$. The second group was asked to drink the routine amount of water. Amniotic fluid index was measured by sonography and Doppler study for the two groups after $12 \mathrm{~h}$.

\section{Technique of US:}

\section{Amniotic fluid index:}

The uterus was divided into four quadrants by using the umbilicus as one reference point dividing the uterus into upper and lower halves, and the linea nigra was then used to divide the uterus into right and left halves. A convex transducer was then placed on the maternal abdomen along the longitudinal axis of the mother, with the transducer head being perpendicular to the floor in each of the four uterine quadrants. The vertical diameter of the largest amniotic fluid pocket, in each uterine quadrant once identified, was measured. The measurements obtained from each uterine quadrant were summed up to represent the amniotic fluid index. Amniotic fluid index $<5 \mathrm{~cm}$ was labeled as low amniotic fluid volume, while amniotic fluid index > 5.1 to $20 \mathrm{~cm}$ was labeled as normal amniotic fluid volume and amniotic fluid index > $20 \mathrm{~cm}$ was labeled as high amniotic fluid volume. For each amniotic fluid index, the mean of two measurements was used for analysis.

\section{Doppler study:}

The angle between the ultrasonographic beam and the direction of blood flow was always <30 degrees. The Doppler signals from the studied arteries were recorded with a $3.5 \mathrm{MHz}$ curved array duplex transducer. Doppler indices were calculated by the dedicated software supplied within the Doppler equipment. The average value of at least three consecutive waveforms was calculated.

\section{Umbilical artery Doppler:}

The uterine contents were scanned to select an area of amniotic cavity with several loops of the umbilical cord. Ideally, these cord loops should not be close to the cord insertion. Then, using a pulsed-wave-Doppler on a free loop of the cord, and the characteristic sound and shape of the umbilical artery was identified. When the screen showed several waveforms of similar height, the image was frozen. The umbilical artery Doppler indices from at least 3 consecutive waveforms was obtained and averaged to determine pulsatility index (PI) where [PI = (maximal systolic velocity - least diastolic velocity) / average]. A minimum of 3 separate readings were averaged before the final values were obtained. Because of the potential effect of the fetal breathing movements on waveform variability, recordings were performed during periods of fetal apnea.

\section{Uterine artery Doppler:}

Uterine artery was examined by directing the probe to the parauterine area in the region of the lower uterine segment. Pulsatility index was calculated by the dedicated software 
supplied within the Doppler equipment. Baseline maternal blood sample was taken immediately before the hydration for direct measurement of hematocrit which was performed by standard laboratory techniques. At the end of the 2-hour hydration period and12 hours after hydration blood samples was taken and analyzed. Baseline maternal urine sample was taken immediately before the hydration for direct measurement of specific gravity, which was performed by standard laboratory techniques. At the end of the 2-hour hydration period, the patient was instructed to micturate again and then the next sample was collected for analysis. Urine samples were taken also 12 hours after hydration for analysis.
(Statistical Package for Social Sciences) version 22 for Windows ${ }^{\circledR}$ (IBM SPSS Inc, Chicago, IL, USA). Data were tested for normal distribution using the Shapiro Walk test. Quantitative data were expressed as mean \pm SD (Standard deviation). Independent samples t-test was used to compare between two independent groups of normally distributed variables (parametric data) while Mann Whitney U test was used for non-normally distributed Data (non-parametric data). For comparison of quantitative data between two related groups, paired-samples t-test. or Wilcoxon test were used for parametric and non-parametric data respectively. For all tests, $\mathrm{P}$ values $<0.05$ are considered significant.

\section{Statistical analysis:}

The collected data were coded, processed and analyzed using the SPSS

\section{RESULTS}

The mean age of the included cases was 25.34 and 24.17 years for the group receiving oral rehydration therapy and control group respectively ( $p>0.05)$. Furthermore, the mean BMI was 22.7 and
$22.8 \mathrm{~kg} / \mathrm{m} 2$ respectively. No statistically significant difference was detected between both groups regarding weight or BMI ( $p$ >0.05) (Table 1).

Table (1): Demographic data of the cases within the study groups

\begin{tabular}{|c|c|c|c|}
\hline Parameter Groups & $\begin{array}{c}\text { Group A } \\
\text { (oral rehydration group) } \\
(\mathbf{n = 2 0})\end{array}$ & $\begin{array}{c}\text { Group B } \\
\text { (control group) } \\
(\mathbf{n = 2 0})\end{array}$ & P value \\
\hline Age (years) & $25.34 \pm 3.17$ & $24.17 \pm 2.94$ & $>0.05$ \\
\hline Weight $(\mathrm{Kg})$ & $79.16 \pm 9.15$ & $74.45 \pm 10.92$ & $>0.05$ \\
\hline BMI $\left(\mathrm{kg} / \mathrm{m}^{2}\right)$ & $22.7 \pm 1.8$ & $22.8 \pm 1.9$ & $>0.05$ \\
\hline
\end{tabular}

The mean pulse was 90.34 and 87.14 bpm for both groups respectively. Mean arterial blood pressure was $93.42 \mathrm{mmHg}$ for group A while it was $90.62 \mathrm{mmHg}$ for group B. In addition, the mean temperature for the included cases was
37.09 and 37.46 respectively. While group A had a mean hemoglobin value of 10.8 $\mathrm{gm} / \mathrm{dl}$ and mean hematocrit value of 32.2 , the other group had a mean hemoglobin and hematocrit values of $11.2 \mathrm{gm} / \mathrm{dl}$ and 31.6 respectively. Neither of the 
previously studies parameters were groups $(\mathrm{p}>0.05)$ (Table 2). statistically different between the study Table (2): Items of initial investigation and laboratory findings

\begin{tabular}{|l|c|c|c|}
\hline Parameter & $\begin{array}{c}\text { Group A } \\
\text { Groups }\end{array}$ & $\begin{array}{c}\text { Group B } \\
\text { (control group) } \\
(\mathbf{n = 2 0})\end{array}$ & P value \\
\hline Pulse $(\mathrm{bpm})$ & $90.34 \pm 19.48$ & $87.14 \pm 21.17$ & $>0.05$ \\
\hline Mean ABP $(\mathrm{mmHg})$ & $93.42 \pm 20.12$ & $90.62 \pm 18.1$ & $>0.05$ \\
\hline Temperature $\left({ }^{\circ} \mathrm{C}\right)$ & $37.09 \pm 0.98$ & $37.46 \pm 0.23$ & $>0.05$ \\
\hline Hemoglobin $(\mathrm{gm} / \mathrm{dl})$ & $10.8 \pm 1.6$ & $11.2 \pm 1.4$ & $>0.05$ \\
\hline Hematocrit & $32.2 \pm 2.9$ & $31.6 \pm 3.1$ & $>0.05$ \\
\hline
\end{tabular}

The mean AFI in group A before treatment was $3.6 \pm 1.3$ and in group $B$ it was $3.4 \pm 1.5$ with no significant difference between the two groups $(\mathrm{p}=0.367)$. The mean AFI in group A after treatment was $8.6 \pm 1.3$ and in group $B$ it was $5.8 \pm 1.2$ with statistically significant difference between the two groups $(\mathrm{p}<0.001)$. There was a statistically significant difference between the values of AFI before and after treatment in group A $(\mathrm{p}<0.001)$, but not in group B $(0.052)$ (Table 3).

Table (3): AFI analysis before after treatment

\begin{tabular}{|l|c|c|c|}
\hline Parameter & $\begin{array}{c}\text { Group A } \\
\text { Groups }\end{array}$ & $\begin{array}{c}\text { Group B } \\
\text { (oral rehydration group) } \\
(\mathbf{n = 2 0})\end{array}$ & $\begin{array}{c}\text { P value } \\
(\mathbf{n = 2 0})\end{array}$ \\
\hline AFI before treatment & $3.6 \pm 1.3$ & $3.4 \pm 1.5$ & 0.367 \\
\hline AFI after treatment & $8.6 \pm 1.3$ & $5.8 \pm 1.2$ & $>0.01$ \\
\hline P1 & $<0.001 *$ & 0.052 & \\
\hline
\end{tabular}

The mean resistive index in group $\mathrm{A}$ before treatment was $0.643 \pm 0.021$ and in group B it was $0.624 \pm 0.036$ with no significant difference between the two groups $(p=0.096)$. The mean resistive index in group A after treatment was $0.684 \pm 0.11$ and in group B it was 0.679 \pm 1.2 with statistically significant difference between the two groups $(p=0.235)$. There was no statistically significant difference between the values of AFI before and after treatment in both group A $(p=0.126)$, and in group $B$ (0.098) (Table 4).
The mean pulsatility index of the umbilical artery in group A before treatment was $0.862 \pm 0.034$ and in group $B$ it was $0.842 \pm 0.029$ with no significant difference between the two groups $(p=0.234)$. The mean pulsatility index of the umbilical artery in group A after treatment was $0.72 \pm 0.17$ and in group $\mathrm{B}$ it was $0.70 \pm 0.31$ with no statistically significant difference between the two groups $(p=0.386)$. There was no statistically significant difference between the values of PI before and after treatment in both group $\mathrm{A}(\mathrm{p}=0.076)$, and in group B (0.063) (Table 4). 
Table (4): Analysis of resistance index (RI) and pulsatility index (PI) of umbilical artery by Doppler before and after treatment

\begin{tabular}{|l|c|c|c|}
\hline \multicolumn{1}{|c|}{ Groups } & $\begin{array}{c}\text { Group A } \\
\text { Parameter }\end{array}$ & $\begin{array}{c}\text { Group B } \\
\text { (control group) } \\
(\mathbf{n = 2 0})\end{array}$ & P value \\
\hline $\begin{array}{l}\text { Resistance index (RI): } \\
\text { RI before treatment }\end{array}$ & $0.643 \pm 0.021$ & $0.624 \pm 0.036$ & $<0.05$ \\
\hline RI after treatment & $0.684 \pm 0.11$ & $0.679 \pm 1.2$ & $>0.05$ \\
\hline P1 & $>0.05$ & $>0.05$ & \\
\hline $\begin{array}{l}\text { Pulsatility index (PI): } \\
\text { PI before treatment }\end{array}$ & $0.862 \pm 0.034$ & $0.842 \pm 0.029$ & $>0.05$ \\
\hline PI after treatment & $0.72 \pm 0.17$ & $0.70 \pm 0.31$ & $>0.05$ \\
\hline P1 & $>0.05$ & $>0.05$ & \\
\hline
\end{tabular}

$P$ refers to the $\mathrm{p}$ value between the two groups

P1 refers to the difference between two time points at the same group

The mean pulsatility index of the uterine artery in group A before treatment was $0.94 \pm 0.04$ and in group B it was $0.91 \pm 0.02$ with no significant difference between the two groups $(\mathrm{P}>0.05)$. The mean pulsatility index of the uterine artery in group A after treatment was $0.83 \pm 0.17$ and in group B it was $0.82 \pm 0.31$ with no statistically significant difference between the two groups $(\mathrm{P}>0.05)$. There was a statistically significant difference between the values of PI before and after treatment in group $A(p>0.05)$ but not in group $B(P$ $>0.01$ ) (Table 5).
The mean pulsatility index of the renal artery in group A before treatment was $2.11 \pm 0.87$ and in group B it was $2.05 \pm$ 0.76 with no significant difference between the two groups $(\mathrm{P}>0.05)$. The mean pulsatility index of the renal artery in group A after treatment was $1.96 \pm 0.63$ and in group B it was $1.99 \pm 0.59$ with no statistically significant difference between the two groups $(\mathrm{P}>0.05)$. There was a statistically significant difference between the values of PI before and after treatment in group $\mathrm{A}(\mathrm{P}>0.05)$ but not in group $\mathrm{B}$ ( $\mathrm{P}>0.05)$ (Table 5).

Table (5): Analysis of pulsatility index (PI) of uterine artery and renal artery by Doppler before and after treatment

\begin{tabular}{|c|c|c|c|}
\hline$\overbrace{\text { Parameter }}^{\text {Groups }}$ & $\begin{array}{c}\text { Group A } \\
\text { (oral rehydration group) } \\
(\mathbf{n}=\mathbf{2 0})\end{array}$ & $\begin{array}{c}\text { Group B } \\
\text { (control group) } \\
(\mathbf{n}=\mathbf{2 0}) \\
\end{array}$ & $P$ value \\
\hline $\begin{array}{l}\text { Uterine artery: } \\
\text { PI before treatment }\end{array}$ & $0.94 \pm 0.04$ & $0.91 \pm 0.02$ & $<0.05$ \\
\hline PI after treatment & $0.83 \pm 0.17$ & $0.82 \pm 0.31$ & 0.126 \\
\hline $\mathrm{P} 1$ & $0.042 *$ & $>0.05$ & \\
\hline $\begin{array}{l}\text { Renal artery: } \\
\text { PI before treatment }\end{array}$ & $2.11 \pm 0.87$ & $2.05 \pm 0.76$ & 0.106 \\
\hline PI after treatment & $1.96 \pm 0.63$ & $1.99 \pm 0.59$ & 0.634 \\
\hline $\mathrm{P} 1$ & $0.035^{*}$ & $>0.05$ & \\
\hline
\end{tabular}

$P$ refers to the $p$ value between the two groups

$\mathrm{P} 1$ refers to the difference between two time points at the same group 


\section{DISCUSSION}

The current study included 20 cases in each group. The mean age of the included cases was 25.34 and 24.17 for the rehydration and control groups respectively. There was no significant difference between the two groups regarding that parameter.

Another study that evaluated the same perspective included a total of 136 cases (68 cases in each group). The mean age of the included cases was 26.5 and 27.0 years for intervention and nonintervention groups respectively. Like our study, no significant difference was detected between the two groups regarding patient age (Cicily et al., 2017).

In our study, the mean BMI of the intervention and non-intervention groups were 22.7 and $22.8 \mathrm{~kg} / \mathrm{m}^{2}$ respectively. In another Egyptian study that compared three different methods of maternal hydration in management of oligohydramnios, average BMI of the mothers in the i.v. isotonic group was 28.1 $\pm 3.0 \mathrm{~kg} / \mathrm{m}^{2}$, in the i.v. hypotonic group was $30.1 \pm 3.0 \mathrm{~kg} / \mathrm{m}^{2}$, and in the oral water group was $29.2 \pm 2.8 \mathrm{~kg} / \mathrm{m}^{2}$ (Ali and Ahmed, 2018).

The mean gestational age of the included cases in the present study was 36.3 and 36.05 weeks for the intervention and non-intervention groups respectively. In a previous study conducted by $\mathrm{TJ}$ and his colleagues, the mean value of gestational age of included cases was 35 weeks and 2 days for both groups (Cicily et al., 2017).

In this study, the mean AFI in group A before treatment was $3.6 \pm 1.3$ and in group B was $3.4 \pm 1.5$ with no significant difference between the two groups. The mean AFI in group A after treatment was $8.6 \pm 1.3$ and in group B was $5.8 \pm 1.2$ with statistically significant difference between the two groups. There was a statistically significant difference between the values of AFI before and after treatment in group A, but not in group B indicated the beneficial effect of oral rehydration.

The previously mentioned study that was conducted by Cicily et al. (2017) found that AFI increased by $4 \mathrm{~cm}$ in the group received hydration therapy. Improvement of AFI was detected in $89.7 \%$ of cases while only $8.8 \%$ showed a modest improvement in the nonintervention group. Moreover, the same group showed significant improvement in both maternal and perinatal outcomes. Conversely, the non-intervention group showed much smaller change regarding AFI which was markedly smaller when compared to the intervention group.

In the study conducted by Ghafarnejad and her associates (2010), the mean value of AFI before treatment was 5.08 and 5.21 $\mathrm{cm}$ for intervention and control groups respectively. After receiving hydration therapy, mean AFI has increased to $6.72 \mathrm{~cm}$ (Nevertheless, the control group showed almost no improvement (AFI = $5.25 \mathrm{~cm})$.

AFI showed a significant improvement from $3.96 \mathrm{~cm}$ before intervention up to 7.7 $\mathrm{cm}$ after receiving hydration therapy. These data showed that in pregnancies complicated by isolated oligohydramnios, hydration therapy significantly improves 
the quantity of amniotic fluid (Patrelli et al., 2012).

Furthermore, a randomized controlled trial concluded that maternal oral hydration therapy significantly increases the AFI, reduces the caesarean section rate and improves the fetal outcome (Akter et al., 2012).

A published meta-analysis was conducted to compare the efficacy of different treatment strategies for managing isolated oligohydramnios. Better results were observed when treatment was based on a combination of intravenous (for a period of 1 day) and oral (for a period of at least 14 days) hypotonic fluids (>2000ml) (Gizzo et al., 2015).

Another study reported that oral hydration was effective as intravenous hydration in significantly increase the AFI in third trimester idiopathic oligohydramnios (Nada, 2015).

An Egyptian study has stated that oral hydration is as effective as intravenous hydration in significantly increasing the AFI in the third trimester oligohydramnios (Ali and Ahmed, 2018).

In this study, the pulsatility index of fetal umbilical artery, uterine artery and renal artery was studied by using color Doppler ultrasound before and after hydration to detect any Doppler changes that could have any impact on amniotic fluid volume. There was no statistically significant difference in the mean pulsatility index of the uterine artery between the two groups before and after treatment, and a statistically significant difference between the values of PI before and after treatment in group A but not in group B.
This was in agreement with Zakaria et al. (2018) who showed no statistically significant difference in the pulsatility index of the uterine artery between the two groups before treatment. However, they reported a statistically significant difference in the group received interventional treatment as compared to group received conventional treatment.

In this study, there was no statistically significant difference in the mean pulsatility index of the umbilical artery between the two groups before and after treatment. Also there was no statistically significant between the values before and after treatment in each group separately. This was in agreement with Zakaria et al. (2018) who showed no statistically significant difference in the pulsatility index of the umbilical artery between the two groups before treatment. However, they reported a statistically significant difference in the group received interventional treatment as compared to group received conventional treatment. Ghafarnejad et al. (2010) demonstrated improvement in uteroplacental perfusion detected by Doppler studies after maternal hydration and speculated that the improvement in uteroplacental perfusion could be one of the factors that affect amniotic fluid changes after maternal hydration.

In this study, there was no statistically significant difference in the mean pulsatility index of the renal artery between the two groups before and after treatment. Akdogan and his colleagues (2010) the mean renal artery PI was 2.08 (range 1.5-3.0) in the patients with polyhydramnios who responded to conservative treatment. The mean renal 
artery PI was 2.03 in those patients who did not respond to conservative treatment; however, there were no statically significant correlations between these two groups. Additionally, the mean renal artery PIs were 2.08 and 1.94, respectively, before and after the treatment, in those patients who responded to conservative treatment. However, there were no statistically significant correlations between these two groups.

\section{CONCLUSION}

Oral hydration therapy was effective in improving oligohydramnios status in pregnant women. Moreover, renal and uterine arteries pulsatility indices also improved via such method of management. Nevertheless, umbilical artery pulsatility and resistance indices showed non-significant improvement.

\section{REFERENCES}

1. Akdogan M, Ipek A, Kurt A, Sayit AT and Karaoglanoglu M (2015): Renal Artery Doppler Findings in the Patients with Polyhydramnios before and after the Conservative Treatment. The Eurasian Journal of Medicine, 47(2): 85-89.

2. Akter M, Kabir N, Shah M, Islam F and Tasnim $S$ (2012): Effect of maternal oral hydration therapy in oligohydramnios. Mymensingh Medical Journal: MMJ, 21(4): 723728.

3. Ali HAEF and Ahmed SRH (2018): The effect of oral versus intravenous fluid therapy on maternal and neonatal outcomes for women with oligohydramnios. Egyptian Nursing Journal, 15(3): 228-231.
4. Cicily TJ, Sams S and Gopal AK (2017): Effect of hydration therapy on oligohydramnios. International Journal of Reproduction, Contraception, Obstetrics and Gynecology, 6(5): 18011805.

\section{Friedman $P$ and Ogunyemi $D$ (2018):} Oligohydramnios Obstetric Imaging: Fetal Diagnosis and Care, Elsevier. Pp. 511-515.

6. Ghafarnejad M, Tehrani MB, Anaraki FB, Mood NI and Nasehi L (2010): Oral hydration therapy in oligohydramnios. Journal of Obstetrics and Gynaecology Research, 35(5): 895-900.

7. Gizzo S, Noventa M, Vitagliano A, Dall'Asta A, D'Antona $D$ and Aldrich CJ (2015): An update on maternal hydration strategies for amniotic fluid improvement in isolated oligohydramnios and normohydramnios: evidence from a systematic review of literature and meta-analysis. PloS one, 10(12): e0144334.

8. Hesson, A. and Langen, E. (2017): Outcomes in Oligohydramnios. Obstetrics \& Gynecology, 129(5): 190195.

\section{Hughes DS and Magann EF (2017):} Antenatal fetal surveillance Assessment of the AFV. Clinical Obstetrics \& Gynaecology, 38: 12-23.

10. Nada $Z$ (2015): Oral and intravenous maternal hydration in third trimester Idiopathic oligohydramnios: effects and duration. IOSR Journal of Nursing and Health Science, 4(5): 2225. 
11. Patrelli TS, Gizzo S, Cosmi E, Carpano MG, Di Gangi $S$ and Pedrazzi G (2012): Maternal hydration therapy improves the quantity of amniotic fluid and the pregnancy outcome in third-trimester isolated oligohydramnios: a controlled randomized institutional trial. Journal of Ultrasound in Medicine, 31(2): 239244.

\section{Rabie N, Magann E, Steelman S} and Ounpraseuth $S$ (2017): Oligohydramnios in complicated and uncomplicated pregnancy: a systematic review and meta-analysis. Ultrasound in Obstetrics \& Gynecology, 49(4): 442-449.

\section{Rabinovich A, Holtzman $K$,} Shoham-Vardi I, Mazor $M$ and Erez O (2019): Oligohydramnios is an independent risk factor for perinatal morbidity among women with preeclampsia who delivered preterm. The Journal of Maternal-Fetal \& Neonatal Medicine, 32(11): 1776-1782.
14. Rawat $R$ (2015): effect of Maternal Oral Hydration Therapy on Maternal and Perinatal Outcome in Isolated Oligohydramnios. Journal of South Asian Federation of Obstetrics and Gynaecology, 7(2): 64-67.

15. Uche EB, Chijioke O, Chukwuemeka OE, Robinson OC and Anderson UK (2018): Incidence of Oligohydramnios-Amniotic Fluid Index (AFI) Versus Single Deepest Pocket (SDP). Asian Journal of Medicine and Health, 10: 1-8.

16.Zakaria AEMM, Sedek AEMA and Abohassan NA (2018): Amniotic Fluid Changes and Doppler Studies in Unexplained Oligohydramnios before and after Intravenous Maternal Hydration. Egyptian Journal of Hospital Medicine, 73(2): 6052-6063. 


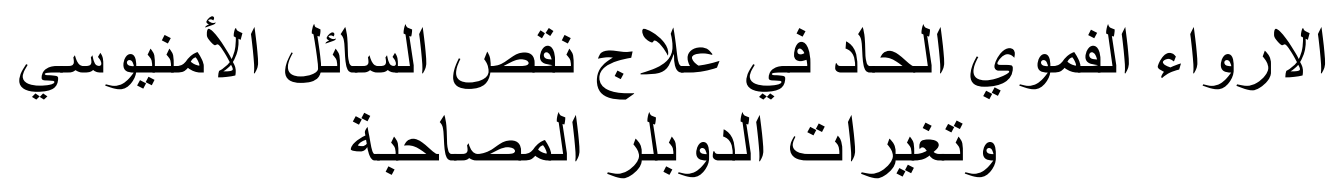

محمد علاء فرغل, عبد المنعم محمد زكريا، عبد المصيف عبد الحميد صديق

قسم أمراض النساء والولادة، كلية الطب, جامعة الأزهر

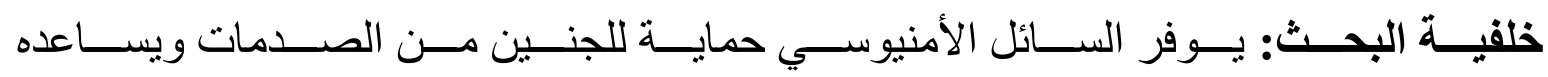

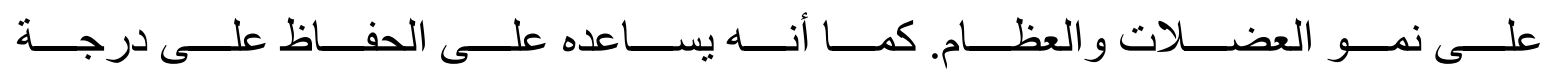

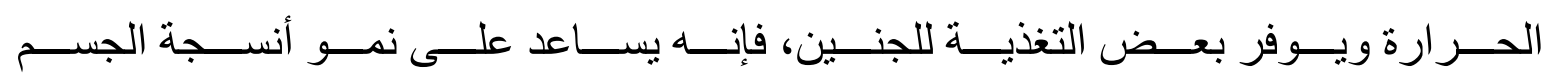

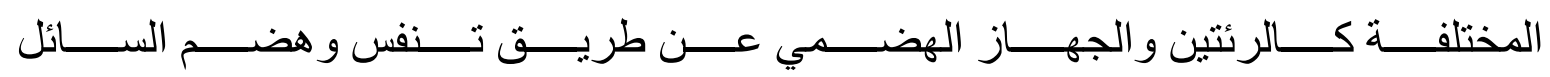

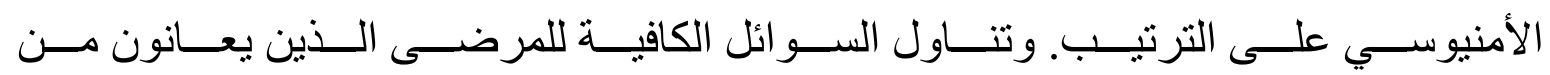

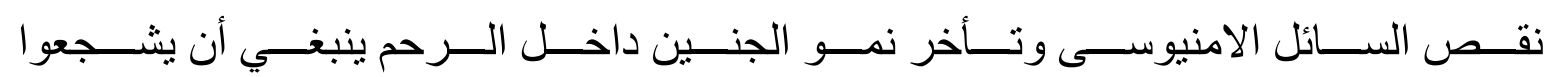

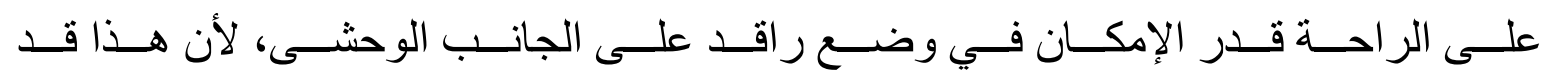
يساعد أيضا على زيادة الامداد الواصل للجنين وكذللك تحسين نمو الجنين.

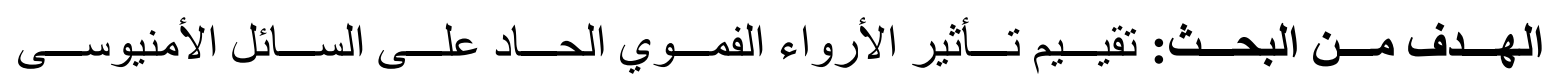
الذي يحيط بالجنين وتغير ات الدوبل فلر المرتبطة بها.

المريضــات وطــرق البحــث: إثـــتملت الدر اســـة علــى 40 امـــر أة حامــل فـــى العيــادة

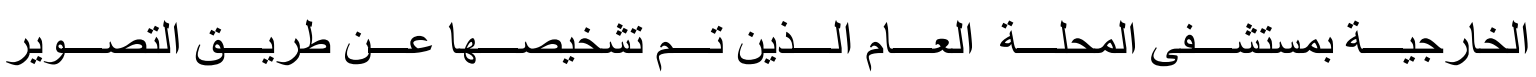

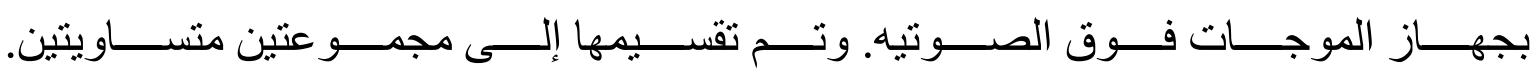

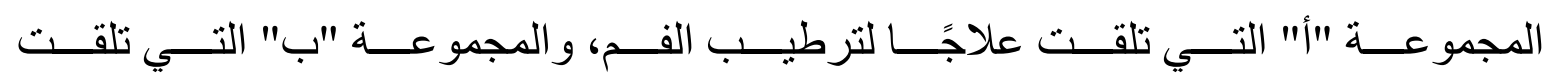

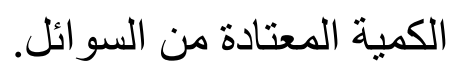

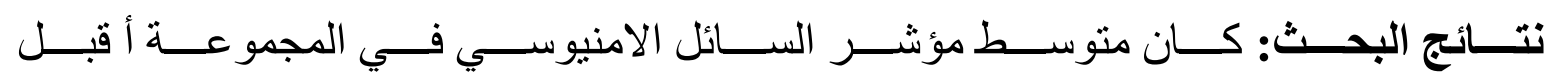

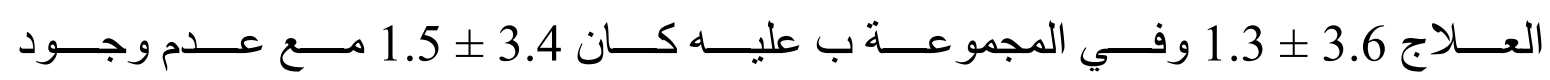

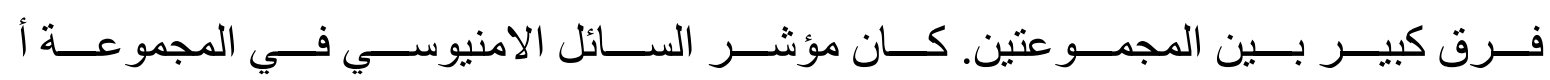

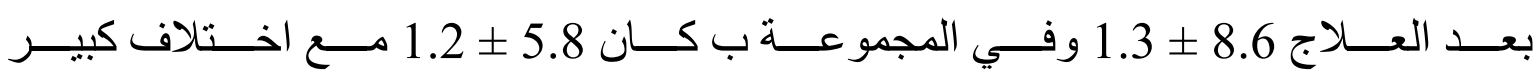

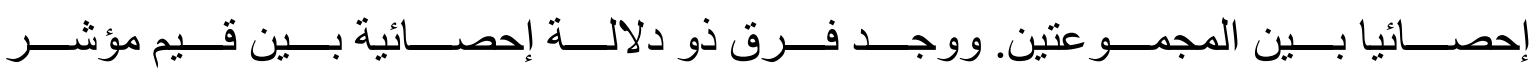

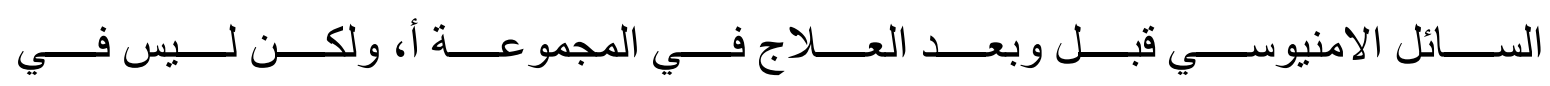




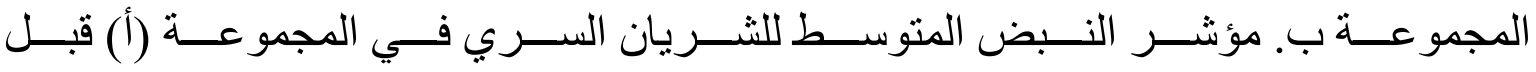

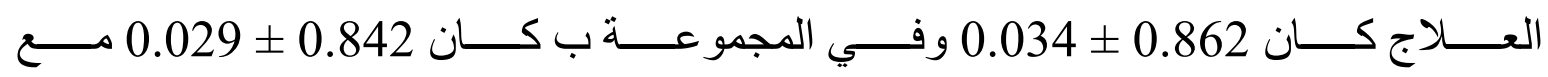

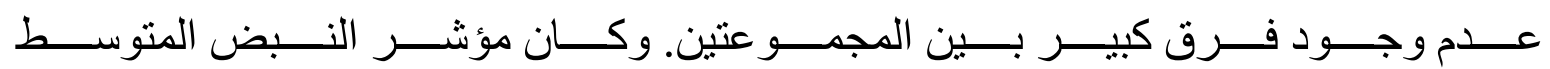

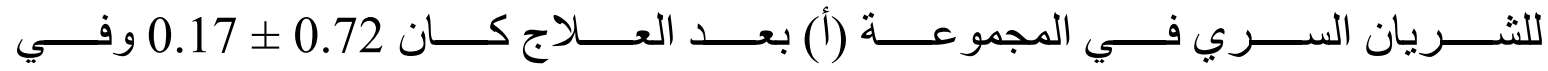

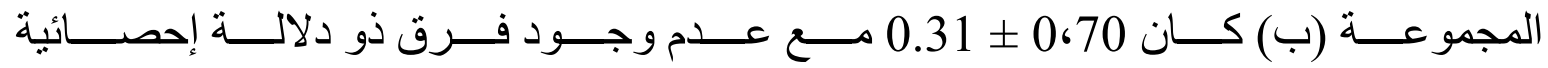

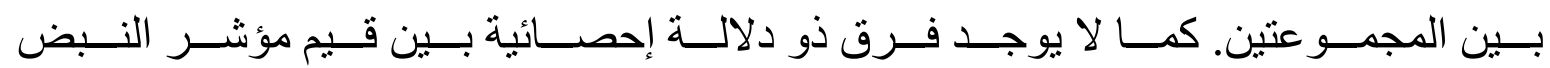

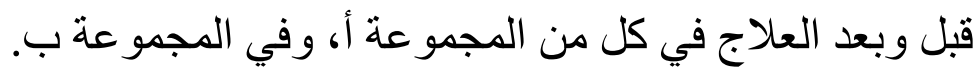

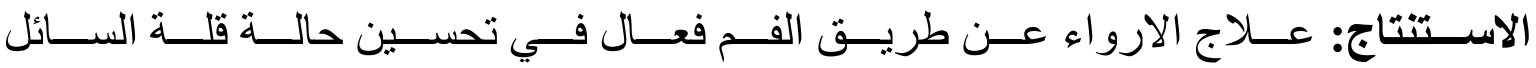

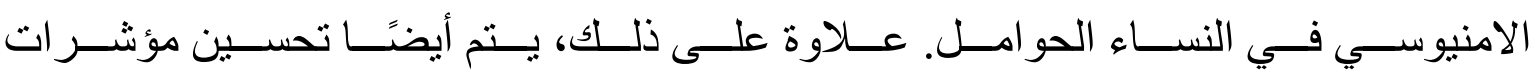

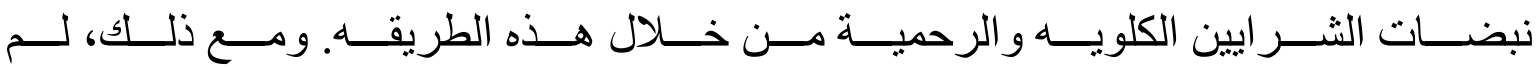
تظهر نبض الثريان السري ومؤشرات مقاومنة تحسنا كبيرا. 